\author{
Research Paper No. 2005/31
}

\title{
On the Causal Links between FDI and Growth in Developing Countries
}

\author{
Henrik Hansen and John Rand*
}

June 2005

\begin{abstract}
We analyse the Granger causal relationships between foreign direct investment (FDI) and GDP in a sample of 31 developing countries covering 31 years. Using estimators for heterogeneous panel data we find bi-directional causality between the FDI-to-GDP ratio and the level of GDP. FDI has a lasting impact on GDP, while GDP has no longrun impact on the FDI-to-GDP ratio. In that sense FDI causes growth. Furthermore, in a model for GDP and FDI as a fraction of gross capital formation (GCF) we also find long-run effects from FDI to GDP. This finding may be interpreted as evidence in favour of the hypotheses that FDI has an impact on GDP via knowledge transfers and adoption of new technology.
\end{abstract}

Keywords: economic growth, foreign direct investment, Granger causality, panel data JEL classification: O4, F21, C33

\section{Copyright @ UNU-WIDER 2005}

* Both authors are affiliated with the Institute of Economics, University of Copenhagen and Development Economics Research Group (DERG)

This is a revised version of the paper originally presented at the WIDER Conference on Sharing Global Prosperity, 6-7 September 2003, Helsinki.

UNU-WIDER gratefully acknowledges the financial contributions to its research programme by the governments of Denmark (Royal Ministry of Foreign Affairs), Finland (Ministry for Foreign Affairs), Norway (Royal Ministry of Foreign Affairs), Sweden (Swedish International Development Cooperation Agency — Sida) and the United Kingdom (Department for International Development). 
The World Institute for Development Economics Research (WIDER) was established by the United Nations University (UNU) as its first research and training centre and started work in Helsinki, Finland in 1985. The Institute undertakes applied research and policy analysis on structural changes affecting the developing and transitional economies, provides a forum for the advocacy of policies leading to robust, equitable and environmentally sustainable growth, and promotes capacity strengthening and training in the field of economic and social policy making. Work is carried out by staff researchers and visiting scholars in Helsinki and through networks of collaborating scholars and institutions around the world.

www.wider.unu.edu

publications@wider.unu.edu

UNU World Institute for Development Economics Research (UNU-WIDER)

Katajanokanlaituri 6 B, 00160 Helsinki, Finland

Camera-ready typescript prepared by Liisa Roponen at UNU-WIDER

The views expressed in this publication are those of the author(s). Publication does not imply endorsement by the Institute or the United Nations University, nor by the programme/project sponsors, of any of the views expressed. 


\section{Introduction}

The inflow of foreign direct investment (FDI) increased rapidly during the late 1980s and the 1990s in almost every region of the world revitalizing the long and contentious debate about the costs and benefits of FDI inflows. On one hand many would argue that, given appropriate policies and a basic level of development, FDI can play a key role in the process of creating a better economic environment. On the other hand potential drawbacks do exist, including a deterioration of the balance of payments, as profits are repatriated having negative impacts on competition in national markets. At present the consensus seems to be that there is a positive association between FDI inflows and economic growth, provided that receiving countries have reached a minimum level of educational, technological and/or infrastructure development. However, as in many other fields of development economics, there is not universal agreement about the positive association between FDI inflows and economic growth.

Even if one accepts the positive association there is still the question of causality. Does FDI cause (long-run) growth and development or do fast growing economies attract FDI flows as transnational companies search for new market and profit opportunities? Theoretically, neither of the links can be ruled out and this is probably the reason why the causality issue has been the topic of so many recent studies. As documented in section 2, at least six studies precedes our study, and it is reasonable to ask if there is a need for yet another look at causality between FDI and growth in developing countries.

We aim to contribute to the existing literature in three dimensions: First of all we take a close look at the model specification. This is motivated by results obtained by Carkovic and Levine (2002) who argue that once country-specific level differences, endogeneity of FDI inflows and, in particular, convergence effects are taken into account, there is no robust impact from FDI on growth. In essence, Carkovic and Levine change the model specification from a relationship between the FDI-to-GDP ratio (FDI ratio, for short) and the growth rate of GDP to a relationship between the FDI ratio and the log-level of GDP. This change in model formulation makes sense for two reasons. First, the model for the FDI ratio and GDP-growth is a sub-model of the model for the FDI ratio and (log) GDP. Hence, in a statistical sense the second model encompasses the first model. A second reason for starting with Carkovic and Levine's specification is that standard neoclassical growth models with well-defined steady states predict a long-run relation between the levels. Therefore, the model including only the growth rate of GDP excludes the neoclassical growth models by assumption, instead of including these models in conjunction with the endogenous growth models. Thus, when testing for Granger causal relationships between FDI and growth, we specify a vector autoregressive model for the log of GDP and the FDI ratio. We test for Granger causality using annual data and, therefore, include country-specific trends in addition to country-specific levels. This is a natural consequence of analysing the log-level of GDP. Our empirical results, based on estimators that allow for country-specific heterogeneity of all parameters, indicate a strong causal link from the FDI ratio to GDP, also in the long run, whereby mean changes in the FDI ratio cause changes in the level of GDP. GDP also Granger-causes FDI, but we find no impact on the long-run level of the FDI ratio. This result is at odds with other recent studies of Granger causality between FDI and growth. We believe the main reason for the new result is the change in model formulation. 
The second issue we address is the economic significance of FDI inflows, which is natural in light of our finding of statistical significance. In assessing the economic importance of FDI we use the standard Solow model as benchmark. In a Solow model in which capital's share is $1 / 3$ the elasticity of steady state income with respect to the savings ratio is $1 / 2$. Evaluated at a savings ratio of 20 per cent this means that a one percentage point increase in the savings ratio causes a 2.5 per cent increase in the steady state level of income. Our empirical results indicate that a one percentage point increase in the mean of the FDI ratio, on average, causes a 2.25 per cent increase in the GDP level. Hence, FDI appears to be no more or no less growth enhancing than domestic investments.

Knowledge transfers and adoption of new technology are often emphasized as two of the main growth enhancing channels of FDI inflows. But the importance of these channels is not easily quantified in models using (log) levels of FDI or the FDI-to-GDP ratio. ${ }^{1}$ Consequently, in assessing the importance of such channels we reformulate the model and look at FDI as percentage of gross capital formation (GCF). The idea is that the FDI/GCF ratio 'isolates' the knowledge and composition effects of FDI inflows as we condition on gross capital formation. We find FDI/GCF to Granger-cause GDP, indicating a statistical significant composition effect of FDI.

Finally, inspired by previous results on the impact of FDI on growth, we look for systematic patterns in the size of the long-run impact of FDI/GCF on GDP. Based on simple graphical analyses (and regressions) we find no systematic relations between the total impact of FDI and development indicators such as the level of GDP per capita, education, trade or credit. Even though our sample of 31 countries is too small to make conclusive decisions, we do think this is an interesting observation when policymakers and their experts design policies to attract foreign direct investments.

The study is organized as follows: section 2 provides a brief literature review of the association between FDI inflows and economic growth. Section 3 discusses the model used for testing Granger causality, and section 4 summarizes our empirical results. Section 5 concludes.

\section{Recent literature}

During the last decade a number of interesting studies on the role of foreign direct investment in stimulating economic growth has appeared. In an excellent survey de Mello (1997) lists two main channels through which FDI may be growth enhancing. First, FDI can encourage the adoption of new technology in the production process through capital spillovers. Second, FDI may stimulate knowledge transfers, both in terms of labour training and skill acquisition and by introducing alternative management practices and better organizational arrangements. A survey by OECD (2002) underpins these observations and documents that 11 out of 14 studies have found FDI to contribute positively to income growth and factor productivity. Both de Mello and OECD stress one key insight from all the studies reviewed: the way in which FDI affects growth is

1 de Mello (1999) looks at FDI impact on total factor productivity, which is one way of assessing the importance of knowledge transfers. We take a different route that does not rely on TFP calculations. 
likely to depend on the economic and technological conditions in the host country. In particular, it appears that developing countries have to reach a certain level of development, in education and/or infrastructure before they are able to capture potential benefits associated with FDI.

Four studies, relying on a variety of cross-country regressions, have looked into the conditions necessary for identifying FDI's positive impact on economic growth. Interestingly, they stress different, though closely related, aspects of development. First, Blomstrom, Lipsey and Zejan (1994) argue that FDI has a positive growth-effect when a country is sufficiently rich in terms of per capita income. Second, Balasubramanyam, Salisu and Sapsford (1996) emphasize trade openness as being crucial for acquiring the potential growth impact of FDI. Third, Borenztein, De Gregio and Lee (1998) find that FDI raises growth, but only in countries where the labour force has achieved a certain level of education. Finally, Alfaro et al. (2004) draw attention to financial markets as they find that FDI promotes economic growth in economies with sufficiently developed financial markets. However, when Carkovic and Levine (2002) estimate the effects of FDI on growth after controlling for the potential biases induced by endogeneity, country-specific effects, and the omission of initial income as a regressor, the results of these four papers appear to break down. Carkovic and Levine conclude that FDI has no impact on long-run growth.

Another strand of the literature has focused more directly on the causal relationships between FDI and growth and, at least, six studies have tested for Granger causality between the two series using different samples and estimation techniques. Zhang (2001) looks at 11 countries on a country-by-country basis, dividing the countries according to the time-series properties of the data. Tests for long-run causality based on an error correction model, indicate a strong Granger-causal relationship between FDI and GDPgrowth. For six counties where there is no cointegration relationship between the log of FDI and growth, only one country exhibited Granger causality from FDI to growth. Chowdhury and Mavrotas (2003) take a slightly different route by testing for Granger causality using the Toda and Yamamoto (1995) specification, thereby overcoming possible pre-testing problems in relation to tests for cointegration between series. ${ }^{2}$ Using data from 1969 to 2000, they find that FDI does not Granger cause GDP in Chile, whereas there is bi-directional Granger causality between GDP and FDI in Malaysia and Thailand.

De Mello (1999) looks at causation from FDI to growth in 32 countries of which 17 are non-OECD countries. First he focuses on the time-series aspects of FDI and growth, finding that the long-run effect of FDI on growth is heterogeneous across countries. Second, de Mello complements his time-series analysis by providing evidence from panel data estimations. In the non-OECD sample he finds no causation from FDI to growth based on fixed effects regressions with country-specific intercepts, and a negative short-run impact of FDI on GDP using the mean group estimator.

Nair-Reichert and Weinhold (2001) test causality for cross-country panels, using data from 1971 to 1995 for 24 countries. Like de Mello, they emphasize heterogeneity as a serious issue and, therefore, use what they refer to as the mixed fixed and random (MFR) coefficient approach in order to test the impact of FDI on growth. The MFR

2 By fitting the VAR in levels, problems with identifying orders of integration are avoided. 
approach allows for heterogeneity of the long-run coefficients, thereby avoiding the biases emerging from imposing homogeneity on coefficients of lagged dependent variables. They find that FDI on average has a significant impact on growth, although the relationship is highly heterogeneous across countries.

Choe (2003) uses the traditional panel data causality testing method developed by Holtz-Eakin, Newy and Rosen (1988) in an analysis of 80 countries. His results point towards bi-directional causality between FDI and growth, although he finds the causal impact from FDI to growth to be weak.

Finally the study by Basu, Chakraborty and Reagle (2003) addresses the question of the two-way link between FDI and growth. Allowing for country-specific cointegrating vectors as well as individual country and time fixed effects they find a cointegrated relationship between FDI and growth using a panel of 23 countries. Basu, Chakraborty and Reagle emphasize trade openness as a crucial determinant for the impact of FDI on growth, as they find two-way causality in open economies, both in the short and the long run, whereas the long-run causality is unidirectional from growth to FDI in relatively closed economies.

Summing up, the main message to take from this selective survey is that there seems to be a strong relationship between FDI and growth. Although the relationship is highly heterogeneous across countries, the studies generally agree that FDI, on average, has an impact on growth in the Granger causal sense. The main exception from this general conclusion is Carkovic and Levine (2002).

\section{The models}

As can be deducted from the literature survey, the mechanics of testing for Granger causality are well-known. Therefore discussions of the precise specification of the statistical models are often suppressed in empirical analyses. Unfortunately, this leaves room for confusion about the interpretation of the empirical results. To avoid this confusion we specify and discuss our choice of model in this section.

We consider bivariate vector autoregressive (VAR) models for the log of GDP and the FDI ratio, and for the log of GDP and FDI as a percentage of gross capital formation (the FDI/GCF ratio). Data for 31 countries over 31 years (1970-2000) were obtained from the World Development Indicators 2002 and from the UNCTAD FDI database. Details on the data definitions and the precise sources are given in the Appendix.

Let $x_{i t}^{\prime}=\left[\log \left(G D P_{i t}\right), F D I_{i t} / G D P_{i t}\right]$, or $x_{i t}^{\prime}=\left[\log \left(G D P_{i t}\right), F D I_{i t} / G C F_{i t}\right]$, where subscript $i$ indexes countries $(i=1, \ldots, N)$ while $t$ indexes time $(t=1, \ldots, T)$. The VAR-model for $x_{i t}$ is specified as 3

$$
x_{i t}=A_{1 i} x_{i t-1}+A_{2 i} x_{i t-2}+A_{3 i} x_{i t-3}+\mu_{i}+\delta_{i} t+\lambda_{t}+\varepsilon_{i t}
$$

3 In the empirical analyses we found that third-order VAR models had good properties in terms of statistical measures such as information criteria and residual autocorrelation. Therefore, we have chosen present and discuss the specific VAR(3)-model rather than the general VAR( $k$ )-model. 
where $A_{j i}$ are $(2 \times 2)$ matrices of parameters that are allowed to vary across countries, $\mu_{i}$ and $\delta_{i}$ are country specific ( $\left.2 \times 1\right)$ intercept and trend parameters, $\lambda_{t}$ is a $(2 \times 1)$, mean zero, time specific component, assumed to be equal across countries and $\varepsilon_{i t}$ is a (2x 1$)$ idiosyncratic error component assumed to be iid $\left(0, \Omega_{i}\right)$, with country-specific, positive definite covariance matrices.

The reason for including country-specific trends in addition to the country-specific intercept and the time specific component is that we model the log of GDP. If the growth rate of an economy has a non-zero mean then the log of GDP is trending. However, if the trend parameter, $\delta_{i}$, is constant across countries, then the country-specific factor, $\lambda_{t}$, can be redefined to include this common deterministic trend. In this case the result is a standard two-way error component model.

As is well-known, in this model Granger non-causality from FDI to GDP is formulated as the hypothesis

$$
H_{0}(F D I \nrightarrow G D P): a_{12(j i)}=0, \quad j=1,2,3
$$

where $a_{12(j i)}$ are the $(1,2)$-elements in the $A_{j i}$ matrices. If the hypothesis is rejected, we say that FDI Granger causes GDP. The reverse hypothesis of Granger non-causality from GDP to FDI is given as

$$
H_{0}(G D P \nrightarrow F D I): a_{21(j i)}=0, \quad j=1,2,3
$$

Most papers surveyed in section 2 discuss Granger causality between FDI and GDP growth rather than between FDI and the level of GDP. A reformulation of the VAR model, known as the error-correction form, shows that if FDI Granger causes GDP, then it also Granger causes growth. Let

$$
\Pi_{i}=-\left(A_{1 i}+A_{2 i}+A_{3 i}-I\right), \Gamma_{1 i}=-\left(A_{2 i}+A_{3 i}\right), \Gamma_{2 i}=-A_{3 i}
$$

then using the difference operator, $\Delta x_{i t}=x_{i t}-x_{i t-1}$, the VAR-model is given by

$$
\Delta x_{i t}=\Gamma_{1 i} \Delta x_{i t-1}+\Gamma_{2 i} \Delta x_{i t-2}+\Pi_{i} x_{i t-1}+\mu_{i}+\delta_{i} t+\lambda_{t}+\varepsilon_{i t}
$$

In this formulation the dependent variables are the changes in the log of GDP (the growth rate) and the changes in FDI.

Based on economic theory we expect a relationship between the level of GDP and FDI (to either GDP or GCF) as long as the economies are assumed to converge towards steady states. This is in parallel with the relationship between GDP and domestic investment. However, it is possible that economies do not converge towards steady states (e.g. AK-type models of growth) or that FDI has an impact on total productivity sothat a rise in the FDI ratio leads to permanent movements in the steady states. In the latter cases the relationship is between the growth rate of GDP and the FDI ratio. This is a sub-model of the error correction model in which the restriction $\pi_{11(i)}=\pi_{21(i)}=0$ has 
been imposed along with the assumption that $\pi_{22(i)} \neq 0$. Hence, this is a testable hypothesis within the general model.

The error-correction form is a convenient formulation for many other purposes. First of all the hypotheses of Granger non-causality are unchanged by the linearity of the transformation. In the error correction form the hypotheses are

$$
\begin{aligned}
& H_{0}(F D I \nrightarrow G D P): \gamma_{12(j i)}=0 \text { and } \pi_{12 i}=0, \quad j=1,2 \\
& H_{0}(G D P \nrightarrow F D I): \gamma_{21(j i)}=0 \text { and } \pi_{21 i}=0, \quad j=1,2
\end{aligned}
$$

Some authors (e.g., Zhang, 2001 and Basu, Chakraborty and Reagle 2003) partition the Granger non-causality hypothesis into two sub-hypotheses of short- and long-run causality. Short-run causality relates to hypotheses about zeros outside the diagonal in the $\Gamma$-matrices while long-run causality is about off-diagonal zeros in $\Pi$. In the present study we follow the classical notion of Granger causality, and use (5) as the nullhypotheses, whereas we denote the hypotheses about off-diagonal zeros in $\Pi$ as (longrun) neutrality-hypotheses.

The neutrality-hypotheses are interesting because they can be used to relate the crosscountry growth studies using long averages over time and the time-series and panel studies using annual observations. The relationship is given by the moving average representation of the model, which for large $T$ can be approximated by

$$
x_{i t}=C_{i}\left(\mu_{i}+\delta_{i} t\right)+C_{i}(L)\left(\lambda_{t}+\varepsilon_{i t}\right)+(\text { initial conditons })
$$

In this model the long-run impact of FDI on GDP is estimated by $c_{12(i)}$. This effect is akin to the estimated impact in cross-country growth models using long averages. The relation between $C$ and $\Pi$ is, assuming the latter is invertible, given by

$$
C_{i}=-\Pi_{i}^{-1}=\frac{1}{\left|\Pi_{i}\right|}\left[\begin{array}{cc}
-\pi_{22(i)} & \pi_{12(i)} \\
\pi_{21(i)} & -\pi_{11(i)}
\end{array}\right]
$$

From this relation the notion of neutrality is clear: if $\pi_{12(i)}=0$ then $c_{12(i)}=0$ and there is no long-run impact from FDI to the level of GDP. (Likewise, neutrality of GDP with respect to FDI is given from $\pi_{21(i)}=0$.) This shows that cross-country studies using long averages and time-series studies using annual observations may well differ in their conclusion about causality. The first kind of study tests neutrality while the second tests causality (possibly at the business cycle frequencies). It should be clear that the only direct relationship is that Granger non-causality implies neutrality. In the present study we test for both Granger non-causality and neutrality.

Finally, it should be noted that in the empirical analysis below we find cointegration between GDP and FDI and this has implications for the computation and interpretation of the long-run impact matrices $\Pi_{i}$ and $C_{i}$, as both matrices have reduced rank. When $\Pi_{i}$ has reduced rank-in our model rank 1 -it is convenient to write the matrix as a product of two matrices $\Pi_{i}=\alpha_{i} \beta_{i}{ }^{\prime}$, where $\alpha_{i}$ and $\beta_{i}$ are both $(2 \times 1)$-matrices. $C_{i}$ is computed as $C_{i}=\beta_{\perp i}\left(\alpha_{\perp i}^{\prime}\left(I-\Gamma_{1 i}-\Gamma_{2 i}\right) \beta_{\perp i}\right)^{-1} \alpha_{\perp i}^{\prime}$, where $\alpha_{\perp i}$ and $\beta_{\perp i}$ are the orthogonal 
complements to $\alpha_{i}$ and $\beta_{i}$ (Johansen, 1991). In the cointegrated model, the test for neutrality can still be based on the significance of the parameters in the autoregressive representation because a zero-row in $\Pi_{i}$ corresponds to a zero-column in $C_{i}$. If, say, GDP is neutral for the long-run FDI ratio, then $\alpha_{2 i}=0$ and it follows that $\pi_{21 i}=\pi_{22 i}=0$ and $c_{11 i}=c_{21 i}=0$. However, the interpretation of neutrality is somewhat different in cointegrated systems compared to stationary systems. In particular, even if neutrality of GDP with respect to the FDI ratio is accepted, it cannot be concluded that GDP has no impact on the long-run level of the FDI ratio as they are both non-stationary. But, it can be concluded that the level of GDP carries no information about long-run level of the FDI ratio.

\section{Empirical results}

In this section we present the results of our empirical analysis. The main part is devoted to a 'large $T$ ' analysis in which the time-series properties of the data are important. The essence of the large $T$ assumption is that the time-series dimension is assumed to be large enough to be useful in a random coefficient type model. 4 The main drawback of the assumption is the sequence of pre-tests for stationarity and cointegration, which will impact upon the final results of the Granger causality tests. The second approach to testing for Granger causality is a 'large $N$ ' assumption, in which the time-series properties are not analysed explicitly. Instead, the cross-country dimension is assumed to be large enough to lead to asymptotic normality of the estimators regardless of the time-series properties. 5

In the analysis the structure of the relationship between FDI and GDP is assumed to be equal across countries, i.e., the lag structure of the VAR and the time-series properties (non-stationarity and cointegration) are assumed to be identical although the individual parameters are allowed to vary across countries. This is in contrast to many of the causality studies mentioned in section 2 in which results are often given on a countryby-country basis.

\subsection{Time-series properties}

Before testing for Granger causality, we investigate the time-series properties of the GDP and FDI series. ${ }^{6}$ The tests are first performed on a country-by-county basis and subsequently the test statistics are combined to single panel data test statistics. This testing strategy allows all parameters to vary across countries, while preserving the assumption of a common structure.

4 When both $N$ and $T$ tend to infinity, as is required for consistency, the precise condition is that $\sqrt{N} / T \rightarrow 0$ (Hsiao et al., 1999 and Larsson et al., 2001).

5 Here a sufficient condition for consistency and asymptotic normality is that $N / T \rightarrow 0$ as $N$ and $T$ tends to infinity (Alvarez and Arellano 2003).

6 We selected the appropriate lag for each series using the BIC criterion and sequential F-tests. 
Tables 1 and 2 show the tests for unit-roots and cointegration of the series, log GDP, FDI/GDP and FDI/GCF. In the tables we report three test statistics that are all based on the same underlying sets of country-specific tests. For each country we test for unitroots and cointegration using the likelihood ratio test (Johansen, 1988, 1991). The reason for choosing the likelihood ratio test is that Johansen (2002, 2005) has developed a small sample correction of the test and, by simulation, shows that the corrected test statistic performs well in samples of 25-30 observations as long as the time series are not too close to being integrated of order 2. Furthermore, Larsson, Lyshagen and Löthgren (2001) have shown that the standardized likelihood ratio statistic has a limiting normal distribution in heterogeneous panels. In Tables 1 and 2 the Larsson, Lyhagen and Löthgren test based on small sample corrected country-specific statistics is given as 'panel LR'. The test statistic is computed as follows:

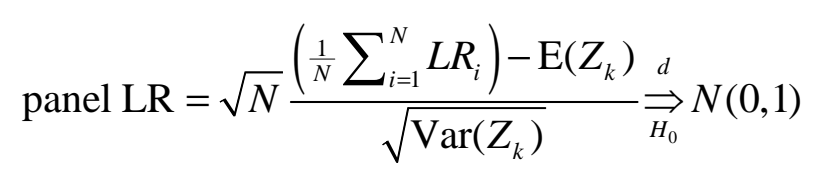

where $E\left(Z_{k}\right)$ and $\operatorname{Var}\left(Z_{k}\right)$ are the mean and variance of the limiting distribution of the country-specific likelihood ratio test. These quantities are found by simulation, as the limiting distribution of the test for unit-roots is non-standard.

In addition to the panel LR, tests we also report two tests, which are based on the $p$ values of the individual country test statistics. ${ }^{7}$ The use of $p$-values in panel unit-root and cointegration tests was proposed by Maddala and Wu (1999). The idea of using $p$ values to test for significance of combined results in independent samples has a long history. 8 In Tables 1 and 2 we report two such test statistics. The first denoted 'log pvalue' is the inverse Chi-square method (Fischer, 1990) while the second is the logit method (George and Mudholkar, 1983):

$$
\begin{aligned}
& \log p=-2 \sum_{i=1}^{N} \log \left(p_{i}\right) \stackrel{d}{\Rightarrow} \chi_{H_{0}}^{2}(2 N) \\
& \operatorname{logit} p=\sqrt{N} \frac{\frac{1}{N} \sum_{i=1}^{N} \log \left(\frac{p_{i}}{1-p_{i}}\right)}{\sqrt{\pi^{2}(5 N+2) /\{3(5 N+4)\}}} \stackrel{d}{\Rightarrow} t(5 N+4)
\end{aligned}
$$

The three test statistics are all based on the maintained hypothesis that the countryspecific errors are independent. 9

Table 1 shows that the null-hypothesis of a unit-root in each of the three series in first differences is rejected at conventional levels of significance. Hence, we find meanstationary differences. In contrast the hypothesis of a unit-root in the levels of the series cannot be rejected.

7 The $p$-values are computed using the Gamma-distribution approximation proposed in Doornik (1998).

8 See Hedges and Olkin (1985) for references.

9 Larsson et al. (2001) do not derive the limiting distribution for the type of model we use. Instead they conjecture that the result holds for this kind of model. This is the reason why we have chosen also to include the two other test statistics. As seen from Tables 1 and 2 there are no discrepancies between the three test statistics. 
Table 2 reports the test statistics for cointegration in the two models, [log GDP, FDI/GDP], and [log GDP, FDI/GCF]. The hypothesis of two-unit roots (no cointegration) is strongly rejected while the hypothesis of one unit-root cannot be rejected. This confirms the non-stationarity of the series and leads to the conclusion that both models have one cointegration vector.

The last row of Tables 1 and 2 reports the percentage of countries in which the nullhypothesis is accepted (Vote counting). We include this statistic to illustrate that the cointegration results are not uniform across countries. One of the differences between the present study and some of the previous studies is that we assume all countries have similar time-series properties, whereas other authors using random coefficient models make use of vote counting and, thereby, assume that the countries havedifferent time-series properties. From Table 2 it appears that the null-hypothesis of no cointegration between log GDP and FDI/GDP is accepted for 22 of the 31 countries when testing at the 5 per cent level of significance. For log GDP and FDI/GCF the fraction is even higher, as there are 23 countries for which we accept the null-hypothesis of no cointegration. So using a country-by-country selection procedure would lead us to look at models for first differenced data. In contrast the panel test statistics are strongly in favour of models for the levels with cointegration constraints.

Table 1

Panel tests for unit-roots in the series

\begin{tabular}{lcccccccc}
\hline & \multicolumn{3}{c}{ First differences } & & \multicolumn{3}{c}{ Levels } \\
\cline { 2 - 5 } \cline { 7 - 8 } & log(GDP) & FDI/GDP & FDI/GCF & & $\log (G D P)$ & FDI/GDP & FDI/GCF \\
\hline Panel LR & 15.40 & 26.28 & 27.46 & & 1.28 & 1.28 & 1.17 \\
& {$[0.00]$} & {$[0.00]$} & {$[0.00]$} & & {$[0.20]$} & {$[0.20]$} & {$[0.24]$} \\
log p-value & 252.43 & 412.37 & 428.24 & & 64.19 & 63.35 & 60.98 \\
& {$[0.00]$} & {$[0.00]$} & {$[0.00]$} & & {$[0.40]$} & {$[0.43]$} & {$[0.51]$} \\
logit p-value & -12.30 & -20.27 & -21.08 & & -0.68 & & -0.69 & -0.54 \\
& {$[0.00]$} & {$[0.00]$} & {$[0.00]$} & & {$[0.50]$} & {$[0.49]$} & {$[0.59]$} \\
\hline Vote counting & 38.71 & 12.90 & 6.45 & & 96.77 & 96.77 & 96.77 \\
\hline
\end{tabular}

Notes: $\quad$ For series in first differences the null-hypothesis is a unit-root without drift against an alternative of mean stationarity. The models include 2 lags. For series in levels the null-hypothesis is a unitroot with drift against an alternative of trend stationarity. The models include 3 lags. $p$-values are reported in brackets.

Table 2

Panel tests for cointegration

\begin{tabular}{lccccc}
\hline & \multicolumn{2}{c}{ Model for log(GDP) and FDI/GDP } & & \multicolumn{2}{c}{ Model for log(GDP) and FDI/GCF } \\
\cline { 2 - 3 } \cline { 5 - 6 } & Two-unit roots & One unit-root & & Two-unit roots & One unit-root \\
\hline Panel LR & 4.88 & 0.18 & & 5.15 & -0.17 \\
& {$[0.000]$} & {$[0.860]$} & & {$[0.00]$} & {$[0.862]$} \\
log p-value & 117.5 & 49.64 & & 123.21 & 46.93 \\
& {$[0.000]$} & {$[0.871]$} & & {$[0.000]$} & {$[0.922]$} \\
logit p-value & -4.46 & 0.307 & & -4.67 & 0.685 \\
& {$[0.000]$} & {$[0.759]$} & & {$[0.000]$} & {$[0.494]$} \\
\hline Vote counting & 70.97 & 100.00 & & 74.19 & 100.00 \\
\hline
\end{tabular}

Notes: The null hypotheses are unit roots with drift. The alternative hypotheses are trend stationarity. $p$ values are reported in brackets. 


\subsection{Granger causality}

Tables 3 and 4 give the results of the Granger causality tests. The regression results in systems (1a)-(1b) in Table 3, and (3a)-(3b) in Table 2 are based on the mean group estimator proposed by Pesaran and Smith (1995). The estimated elements of $\Pi$ are averages of the country-specific estimates; therefore the mean group $\Pi$-matrix does not have reduced rank even though each of the country-specific matrices do. Note also that the row-wise elements of $\Pi$ have identical $t$-values. This is because the variance of $\Pi$ is determined by the variance of $\alpha$, which is constant across the rows.

As seen from Table 3, the system [log GDP, FDI/GDP] has bi-directional causality, when tested at the 5 per cent level. On purely statistical terms the causality from FDI/GDP to GDP seems best determined. In addition we find a strong influence from the levels (the cointegration relation). In contrast the lagged levels of log GDP and FDI/GDP do not carry information for the changes in FDI/GDP. Hence, the hypothesis of neutrality is accepted in the FDI/GDP relation.

In comparing the VAR-model results and cross-country regression results, it is of interest to calculate the non-zero off-diagonal elements of the total impact matrix $C$. In the present model this is the element $\hat{c}_{12}$. The mean group estimate of $\hat{c}_{12}$ is 0.0225 , implying that a one percentage point increase in FDI/GDP leads to a 2.25 per cent increase in GDP in the long-run. Given the sampling variation, this corresponds surprisingly well to the impact of a one percentage point increase in the savings rate in a standard Solow model.

Table 3

Regression results for the log GDP, FDI/GDP system

\begin{tabular}{|c|c|c|c|c|}
\hline \multirow{3}{*}{$\begin{array}{l}\text { Regression } \\
\text { Dependent variable }\end{array}$} & \multicolumn{2}{|c|}{ Mean group estimation } & \multicolumn{2}{|c|}{ Fixed effects estimation } \\
\hline & $(1 a)$ & $(1 b)$ & $(2 a)$ & $(2 b)$ \\
\hline & dlog(GDP) & $\mathrm{d}($ FDI/GDP) & dlog(GDP) & $\mathrm{d}($ FDI/GDP) \\
\hline \multirow[t]{2}{*}{$\operatorname{dlog}(G D P)(t-1)$} & 0.253 & 3.644 & 0.198 & 3.544 \\
\hline & $(6.86)$ & $(2.42)$ & $(5.01)$ & $(3.07)$ \\
\hline \multirow[t]{2}{*}{ dlog(GDP)(t-2) } & -0.107 & 2.064 & 0.002 & 1.068 \\
\hline & $(2.89)$ & $(1.38)$ & $(0.07)$ & $(0.69)$ \\
\hline \multirow[t]{2}{*}{$\mathrm{d}(\mathrm{FDI} / \mathrm{GDP})(\mathrm{t}-1)$} & -0.009 & -0.058 & -0.003 & 0.062 \\
\hline & $(2.59)$ & $(1.20)$ & $(2.73)$ & $(0.78)$ \\
\hline \multirow[t]{2}{*}{$\mathrm{d}($ FDI/GDP)(t-2) } & -0.007 & -0.009 & -0.003 & 0.052 \\
\hline & $(2.06)$ & $(0.19)$ & (3.24) & (1.09) \\
\hline \multirow[t]{2}{*}{$\log (G D P)(t-1)$} & -0.192 & -0.080 & -0.203 & -1.801 \\
\hline & $(9.20)$ & $(0,10)$ & $(8.98)$ & $(1.44)$ \\
\hline \multirow[t]{2}{*}{$($ FDI/GDP)(t-1) } & 0.013 & -0.480 & 0.007 & -0.517 \\
\hline & $(9.20)$ & $(0.10)$ & $(4.83)$ & (3.61) \\
\hline Granger causality ( $p$-values) & 0.000 & 0.019 & 0.000 & 0.010 \\
\hline Neutrality (p-values) & 0.000 & 0.920 & 0.000 & 0.150 \\
\hline
\end{tabular}

Notes: $\quad$ The prefix $d$ indicates first differences of the series and the (t- $i)$ suffix indicates lags $(i=1,2)$. $t$-statistics are reported in parentheses. 
Using regressions (2a) and (2b) in Table 3 we look at the 'robustness' of the mean group estimation. The two regressions are results of fixed effects regressions with country-specific intercepts and trends in addition to time dummies. No information about the time-series properties is imposed on the model.

The fixed effects results are surprisingly close to the mean group results. The point estimates are of the same order of magnitude and in all but two cases there is agreement with respect to the precision of the estimate in terms of statistical significance. There is also agreement about two-way causality and about neutrality in the FDI/GDP relation. 10 The main difference between the mean group and the fixed effects results is found in the estimated long-run impact of FDI/GDP on log GDP $\left(\hat{c}_{12}\right)$. In the fixed effects model, a one percentage point increase in FDI/GDP leads to a 5.88 per cent increase in GDP in the long run, i.e., more than twice the impact found in the mean group estimation with cointegration constraints. However, the hypothesis that the impact is 2.5 per cent cannot be rejected. Overall, the fixed effects regressions support the mean group results.

Table 4

Regression results for the log GDP, FDI/GCF system

\begin{tabular}{|c|c|c|c|c|c|c|}
\hline \multirow[b]{2}{*}{ Regression } & \multicolumn{2}{|c|}{ Mean group estimation } & \multicolumn{2}{|c|}{ Fixed effects estimation } & \multicolumn{2}{|c|}{$\begin{array}{c}\text { Fixed effects estimation, } \\
\text { excl. Pakistan }\end{array}$} \\
\hline & (3a) & $(3 b)$ & $(4 a)$ & $(4 b)$ & $(5 a)$ & $(5 b)$ \\
\hline Dependent variable & dlog(GDP) & $d(\mathrm{FDI} / \mathrm{GCF})$ & $d \log (\mathrm{GDP})$ & $d(\mathrm{FDI} / \mathrm{GCF})$ & $d \log (G D P)$ & $d(\mathrm{FDI} / \mathrm{GCF})$ \\
\hline \multirow[t]{2}{*}{$d \log (G D P)(t-1)$} & 0.242 & 9.607 & 0.195 & 14.077 & 0.194 & 14.096 \\
\hline & $(6.50)$ & $(1.55)$ & $(1.53)$ & $(2.40)$ & $(4.88)$ & $(2.41)$ \\
\hline \multirow[t]{2}{*}{$d \log (G D P)(t-2)$} & -0.118 & 7.732 & -0.003 & 4.159 & -0.008 & 4.322 \\
\hline & $(3.11)$ & $(1.25)$ & $(0.02)$ & $(0.68)$ & $(0.22)$ & $(0.71)$ \\
\hline \multirow[t]{2}{*}{$d(\mathrm{FDI} / \mathrm{GCF})(\mathrm{t}-1)$} & -0.002 & -0.060 & -0.001 & 0.030 & -0.001 & 0.030 \\
\hline & $(2.30)$ & $(1.15)$ & $(0.65)$ & $(0.45)$ & $(3.12)$ & $(0.45)$ \\
\hline \multirow[t]{2}{*}{$d(\mathrm{FDI} / \mathrm{GCF})(\mathrm{t}-2)$} & -0.001 & -0.027 & -0.001 & 0.078 & -0.001 & 0.078 \\
\hline & $(1.63)$ & $(0.55)$ & $(0.73)$ & $(1.67)$ & $(3.09)$ & $(1.73)$ \\
\hline \multirow[t]{2}{*}{$\log (G D P)(t-1)$} & -0.178 & 0.023 & -0.197 & -6.775 & -0.198 & -7.108 \\
\hline & $(8.87)$ & $(0.01)$ & $(2.62)$ & $(1.43)$ & $(8.74)$ & $(1.50)$ \\
\hline \multirow[t]{2}{*}{$(F D I / G C F)(t-1)$} & 0.003 & -0.527 & 0.002 & -0.598 & 0.002 & -0.599 \\
\hline & $(8.87)$ & $(0.01)$ & (1.19) & $(5.48)$ & $(4.93)$ & $(5.59)$ \\
\hline $\begin{array}{l}\text { Granger causality } \\
\text { ( } p \text {-values) }\end{array}$ & 0.000 & 0.150 & 0.660 & 0.051 & 0.000 & 0.050 \\
\hline Neutrality ( $p$-values) & 0.000 & 0.992 & 0.234 & 0.153 & 0.000 & 0.134 \\
\hline
\end{tabular}

Notes: $\quad$ The prefix $d$ indicates first differences of the series and the (t- $i$ ) suffix indicates lags $(i=1,2)$. $t$-statistics are reported in parentheses.

10 This result does not hold for all specifications of the fixed effects model. If the trend slopes are assumed to be equal across countries, we find no Granger causality from GDP to FDI/GDP. When the model is specified for the growth of GDP and FDI/GDP (i.e., replacing the lagged level of log GDP by the third lag of the difference of log GDP), we also find no causality from GDP to FDI/GDP. However, these models do not correspond to the mean group model. 
Next, we turn to the results for log GDP and FDI/GCF. The idea is to quantify if FDI has a composition effect in addition to the increase in gross capital formation. As described in the introduction, this is often assumed to be the main cause of the positive impact of FDI on GDP growth in developing countries.

Regressions (3a) and (3b) are the mean group estimates of the log GDP; FDI/GCF system. In section 4.a it was established that the two series cointegrate and this restriction has been imposed in the mean group model.

In the new system there is one-way causality from FDI to GDP as the hypothesis of Granger non-causality is accepted at the 15 per cent level of significance. Moreover, in agreement with the first system we find neutrality of GDP with respect to the long-run level of FDI/GCF.

The Granger causality and non-neutrality of FDI/GCF with respect to GDP is interesting as it implies an investment composition effect of FDI. A higher ratio of FDI in the gross capital formation has a positive impact on the long-run level of GDP, and thereby on growth. The estimated long-run impact of a one percentage point increase in the ratio $\left(\hat{c}_{12}\right)$ is 0.004 , indicating a 0.4 per cent increase in GDP in the long run. Even though this effect appears small, it can make quite a difference considering the distribution of FDI/GCF across countries and time. A move from the 25th percentile to the 75th percentile is a change in the FDI to GCF ratio of almost 8 percentage points (1.5 to 9.4 per cent). Such a move would generate a 3.2 per cent increase in GDP, based the average impact. We think of this as an economically significant composition effect of FDI, which is somewhat surprising in light of the results for the FDI to GDP ratio.

When the robustness of the mean group results are tested using the fixed effects model we do not get the same agreement as found in the first system. In fact, Table 4 shows that using the fixed effects estimator with country-specific intercepts and trends in addition to time dummies, there are no causal relations when testing at the 5 per cent level. If anything, there is weak support for Granger causality from GDP to FDI, but there is still neutrality, whereby this is information at the business cycle frequencies. The Granger non-causality of FDI with respect to GDP is interesting because the point estimates in the GDP regressions (3a) and (4a) are of the same order of magnitude, thus the result is generated by an inflation of the estimated variances. This points towards a potential outlier problem because outliers have different impacts on the mean group and fixed effects variance estimates. The suspicion is confirmed by a fixed effects regression in which Pakistan is excluded. Regressions (5a)-(5b) clearly show that by excluding Pakistan, we obtain close correspondence between the two estimators, and we find support for Granger causality from FDI to GDP, verifying the mean group results.

Summarizing, we find strong causal effects of FDI on GDP and, even though the impact of FDI on GDP is not significantly larger than the expected impact of domestic investment in a Solow model, we find a significant composition effect in the sense that a higher ratio of FDI in gross capital formation has positive effects on the level of GDP and, hence, on growth. 


\subsection{Searching for systematic variations in the impact of FDI on GDP}

As noted in section 2, heterogeneity of the impact of FDI on GDP has been a recurrent theme in the cross-country literature. In this section we track that literature and look for systematic variations in the estimated total impact of FDI on GDP. Specifically, we investigate (informally) if the impact varies with selected indicators of development.11 We start the analysis by looking for variations in the impact across regions.

Figure 1 plots the 31 estimated total impact coefficients $\left(\hat{c}_{12 i}\right)$, measured as percentages, against the three regions in the sample. The horizontal line in Figure 1 is the mean group estimate ( 0.4 per cent). There are 'outliers' in each of the three regions, notably Cameroon and Ghana in Africa, India and Pakistan in Asia and Brazil and Columbia in Latin America. However, not all of the 'outlying' estimates are significantly different from the overall mean. For Ghana, India and Pakistan the mean group estimate is just outside the 95 per cent confidence band, while the mean group estimate is well inside the confidence band for Cameroon and Brazil.

The most interesting information obtained from Figure 1 is the randomness of the variation in the total impact across regions. In particular, the impact in African countries is not systematically lower than the impact in Asian and Latin American countries. Although this is not our prime concern in the present study, it shows that African countries would potentially benefit from increased FDI flows just as much as the countries in the two other regions.

Figure 1

Total impact of FDI/GCF on GDP by regions

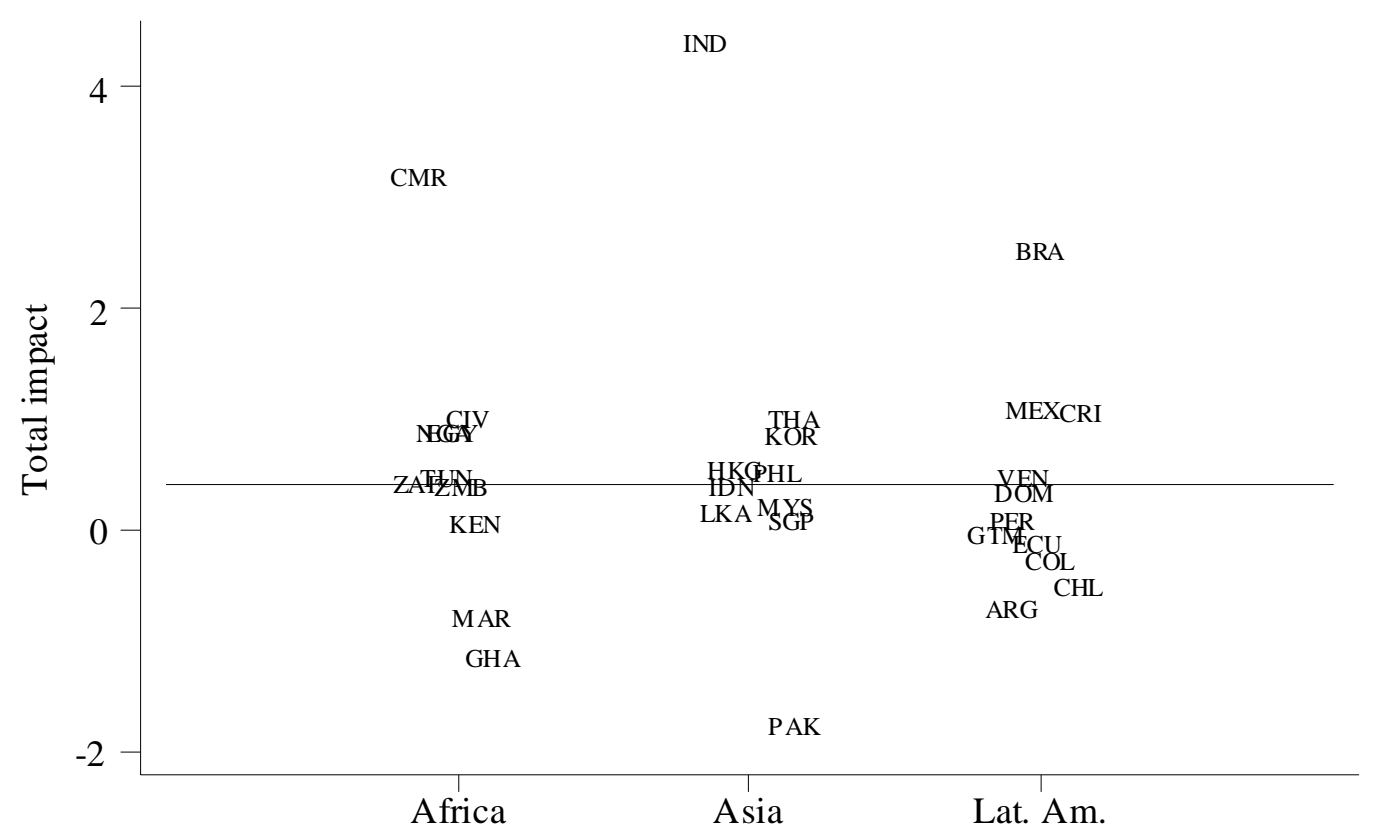

11 The correlation between the estimated country-specific total impact of FDI/GDP and the estimated total impact of FDI/GCF is 0.92 . Therefore we only report the results for FDI/GCF. 
Figure 2

Cross-plots of the total impact of FDI/GCF on GDP and threshold indicators
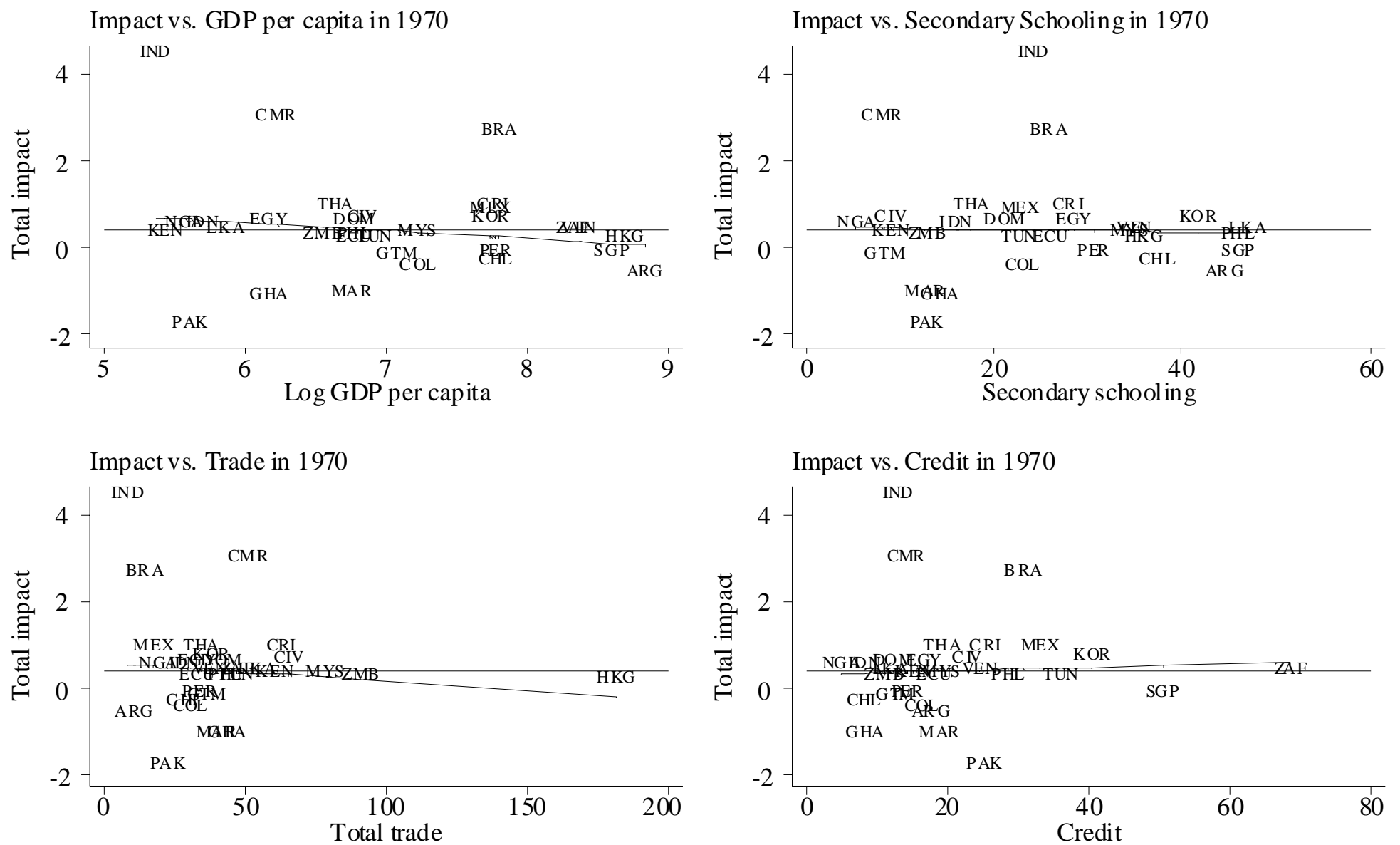
Turning to the different development indicators, we present four cross plots in Figure 2. In each plot the horizontal line is the mean impact while the second line is the regression line. First, following Blomstrom, Lipsey and Zejan (1994) who found important interactions between the level of GDP per capita and FDI, we look for such a relationship in the first panel in Figure 2 by plotting the total impact against the log of GDP per capita in 1970. Second, we look for the human capital threshold proposed by Borenztein, Gregorio and Lee (1998) by plotting the impact against secondary schooling in 1970. Third, we look at trade openness (imports plus exports as a percentage of GDP in 1970), which was emphasized by Balasubramanyam, Salisu and Sapsford (1996) and Basu, Chakrabory and Reagle (2003). Finally, we follow Alfaro et al. (2004) by considering credit in 1970. As seen from Figure 2, there is no clear association between either one of the four indicators and the impact of FDI.12

Needless to say, our sample of 31 countries is too small to make conclusive inference about systematic interactions. Yet, our results seem to support Carkovic and Levine (2002) in that the suggested thresholds are not easily found when country-specific factors and the level of GDP are included in the model. On the other hand we differ from Carkovic and Levine in our finding of a significant long-run impact of FDI on GDP.

\section{Concluding remarks}

Many recent studies analysing foreign direct investment and growth have shown a positive association between FDI and GDP. But there seems to be ambiguity with respect to the direction of causality. In this study we therefore analyse the causal relationship between these variables in a sample of 31 developing countries covering three continents over the time period 1970-2000.

Using a mean group estimator and a model specification that is compatible with the standard neoclassical growth model, we find a strong causal link from FDI to GDPalso in the long run. This result is confirmed using a fixed effects estimator with country-specific time trends. Based on the mean group estimates, we find the impact of FDI on GDP to correspond well with the expected impact in a standard Solow growth model. Hence, FDI appears to be growth enhancing much in the same way as domestic investment. However, it should be noted that the fixed effects model leads to more than twice the impact found using the mean group estimator.

We furthermore analyse if FDI has a composition effect in addition to the increase in gross capital formation and our results indicate a statistically significant composition effect in the sense that a higher ratio of FDI in gross capital formation has positive effects on the level of GDP and hence on growth.

Finally we discuss the often raised issue of heterogeneity of the impact of FDI on GDP. We find no systematic differences in the total impact across regions, implying

12 We have also looked at indicators for institutional quality such as rule of law, control of corruption, political stability and regulatory quality etc. None of the institutional indicators are significantly correlated with the estimated impacts. 
that the expected gain from FDI to the African region should, in principle, equal the impact of FDI in Asia and Latin America. Moreover, by more informal investigations of whether the impact varies with selected indicators of development, we show that the suggested thresholds are not easily found when country-specific factors and the level of GDP are included in the model. Overall we find that, on average, FDI has a significant long-run impact on GDP irrespectively of the level of development. 


\section{Appendix}

Appendix Table A.1

The 31 countries in the sample

\begin{tabular}{lll}
\hline Asia & Latin America & Africa \\
\hline India & Argentina & Egypt \\
Pakistan & Brazil & Morocco \\
Sri Lanka & Chile & Tunisia \\
Hong Kong & Colombia & Cameroon \\
Indonesia & Costa Rica & Cote d'Ivoire \\
Korea, South & Dominican Republic & Ghana \\
Malaysia & Ecuador & Kenya \\
Philippines & Guatemala & Nigeria \\
Singapore & Mexico & South Africa \\
Thailand & Peru & Zambia \\
\end{tabular}

Foreign direct investment figures are obtained from the World Development Indicators (WDI) 2002 from the World Bank and UNCTADs FDI/TNC database. FDI is net inflows of investment, and is the sum of equity capital, reinvestment of earnings, other long-term capital, and short-term capital as shown in the balance of payments. More precisely UNCTAD and WDI use the following FDI definitions:

UNCTAD: FDI inflows comprise capital provided (either directly or through other related enterprises) by a foreign direct investor to a FDI enterprise, or capital received by a foreign direct investor from a FDI enterprise. FDI includes the three following components: equity capital, reinvested earnings and intra-company loans. Equity capital is the foreign direct investor's purchase of shares of an enterprise in a country other than that of its residence. Reinvested earnings comprise the direct investor's share (in proportion to direct equity participation) of earnings not distributed as dividends by affiliates or earnings not remitted to the direct investor. Such retained profits by affiliates are reinvested. Intra-company loans or intra-company debt transactions refer to short- or long-term borrowing and lending of funds between direct investors (parent enterprises) and affiliate enterprises. Data on FDI flows are presented on net bases (capital transactions' credits less debits between direct investors and their foreign affiliates). Net decreases in assets or net increases in liabilities are recorded as credits (with a positive sign), while net increases in assets or net decreases in liabilities are recorded as debits (with a negative sign). Hence, FDI flows with a negative sign indicate that at least one of the three components of FDI is negative and not offset by positive amounts of the remaining components. These are called reverse investment or disinvestment. For more detailed information regarding specific cases or particular countries, please refer to the UNCTAD World Investment Report.

WDI 2002 (Series BX.KLT.DINV.DT.GD.ZS and BX.KLT.DINV.DT.GI.ZS): Foreign direct investment, net inflows (per cent of GDP and per cent of gross capital formation, respectively). FDI is net inflows of investment to acquire a lasting management interest (10 per cent or more of voting stock) in an enterprise operating 
in an economy other than that of the investor. It is the sum of equity capital, reinvestment of earnings, other long-term capital, and short-term capital as shown in the balance of payments. This series shows net inflows in the reporting economy. Gross capital formation (gross domestic investment) is the sum of gross fixed capital formation, changes in inventories, and acquisitions less disposals of valuables.

Differences between the two databases occur, 13 and in this study we have selected the WDI as the primary data source and the UNCTAD FDI/TNC database as the secondary data source. Further information about FDI data can be found on UNCTADs FDI homepage, available at: www.unctad.org/Templates/ Page.asp?intItemID=1923\&lang=1 and on the World Bank WDI data homepage www.worldbank.org/data/wdi2002/index.htm.

Information on real gross domestic product (GDP, 1995 constant USD), secondary school enrolment rates, trade volume and domestic credit to the private sector are all obtained from the WDI 2002.

\section{References}

Alfaro, L., A. Chanda, S. Kalemli-Ozcan, and S. Sayek (2004). 'FDI and Economic Growth: The Role of Local Financial Markets'. Journal of International Economics, 64 (1): 89-112.

Alvarez, J., and M. Arellano (2003). 'The Time Series and Cross-Section Asymptotics of Dynamic Panel Data Estimators’. Econometrica, 71:1121-59.

Balasubramanyam, V. N., M. Salisu, and D. Sapsford (1996). 'Foreign Direct Investment and Growth in EP and IS Countries'. Economic Journal, 106 (434):92105.

Basu, P., C. Chakraborty, and D. Reagle (2003). 'Liberalization, FDI, and Growth in Developing Countries: A Panel Cointegration Approach'. Economic Inquiry, 41 (3): 510-16.

Blomström, M., R. E. Lipsey, and M. Zejan (1994). 'What Explains Developing Country Growth’. NBER Working Paper No. 4132. Cambridge, MA: National Bureau of Economic Research.

Borenztein, E., J. De Gregorio, and J.-W. Lee (1998). 'How Does Foreign Direct Investment Affect Economic Growth'. Journal of International Economics, 45: $115-35$.

Carkovic, M., and R. Levine (2002). 'Does Foreign Direct Investment Accelerate Economic Growth'. Working Paper. City: University of Minnesota Department of Finance. Available at: www//ssrn.com/abstract=314924.

13 UNCTAD collects national official FDI data, and this information is the main source for the reported data on FDI flows. These data are complemented by data obtained from other international organizations including the World Bank, as well as UNCTAD’s own estimates. 
Choe, J. I. (2003). 'Do Foreign Direct Investment and Gross Domestic Investment Promote Economic Growth?'. Review of Development Economics, 7: 44-57.

Chowdhury, A., and G. Mavrotas (2003). 'FDI \& Growth: What Causes What?’ Paper presented at the UNU-WIDER conference on Sharing Global Prosperity, 67 September. Helsinki: UNU-WIDER.

de Mello, L. R. (1997). 'Foreign Direct Investment in Developing Countries and Growth: A Selective Survey’. Journal of Development Studies, 34 (1): 1-34.

de Mello, L. R. (1999). 'Foreign Direct Investment-Led Growth: Evidence from Time Series and Panel Data'. Oxford Economic Papers, 51 (1): 133-51.

Doornik, J. A. (1998). 'Approximations to the Asymptotic Distribution of Cointegration Tests’. Journal of Economic Surveys, 12: 573-93.

Fischer, R. A. (1990). Statistical Methods, Experimental Design And Scientific Inference. New York: Oxford University Press.

George, E. O., and G. S. Mudholkar (1983). 'On the Convolution of Logistic Random Variables'. Metrika, 30: 1-14.

Hedges, L. V., and I. Olkin (1985). Statistical Methods For Meta-Analysis. New York: Academic Press.

Holtz-Eakin, D., W. Newey, and H. S. Rosen (1988). 'Estimating Vector Autoregressions with Panel Data'. Econometrica, 56 (6): 1371-95.

Hsiao, C., M. H. Pesaran, and A. K. Tahmiscioglu (1999). 'Bayes Estimation Of Short-Run Coefficients in Dynamic Panel Data Models', in C. Hsiao, L. F. Lee, K. Lahiri, and M. H. Pesaran (eds), Analysis of Panels and Limited Dependent Variables Models. Cambridge: Cambridge University Press, 268-96.

Johansen, S. (1988). 'Statistical Analysis of Cointegration Vectors'. Journal of Economic Dynamics and Control, 12: 231-54.

Johansen, S. (1991). 'Estimation and Hypothesis Testing of Cointegration Vectors in Gaussian Autoregressive Models’. Econometrica, 59:1551-80.

Johansen, S. (2002). 'A Small Sample Correction of the Test for Cointegrating Rank in the Vector Autoregressive Model'. Econometrica, 70: 1929-61.

Johansen, S. (2005). 'Asymptotic and Finite Sample Properties of the Dickey-Fuller Test', in A. Welfe (ed.), New Directions in Macromodelling, Chapter 6. Amsterdam: Elsevier.

Larsson, R., J. Lyhagen, and M. Löthgren (2001). 'Likelihood-based Cointegration Tests in Heterogeneous Panels'. Econometrics Journal, 4 (41): 109-42.

Maddala, G. S., and S. Wu (1999). 'A Comparative Study of Unit Root Tests with Panel Data and a New Simple Test'. Oxford Bulletin of Economics and Statistics, 61: 631-52.

Nair-Reichert, U., and D. Weinhold (2001). 'Causality Tests for Cross-Country Panels: A New Look on FDI and Economic Growth in Developing Countries'. Oxford Bulletin of Economics and Statistics, 63: 153-71. 
OECD (2002). 'Foreign Direct Investment for Development: Maximizing Benefits, Minimizing Costs’. OECD Policy Brief. Paris: OECD.

Pesaran, M. H., and R. Smith (1995). 'Estimating Long-run Relationships from Dynamic Heterogeneous Panels'. Journal of Econometrics, 68: 79-113.

Toda, H. Y., and T. Yamamoto (1995). 'Statistical Inference in Vector Autoregressions with Possible Integrated Processes’. Journal of Econometrics, 66: 225-50.

Zhang, K. H. (2001). 'Does Foreign Direct Investment Promote Economic Growth? Evidence from East Asia and Latin America'. Contemporary Economic Policy, 19, 175-85. 